\title{
Partial Zone II Resuscitative Endovascular Balloon Occlusion of the Aorta in Management of Multiple Trauma with Combined Abdominal and Pelvic Injury
}

Emiliano Gamberini ${ }^{1 *}$, Nicola Fabbri ${ }^{2}$, Andrea Taioli ${ }^{3}$, Costanza Martino ${ }^{1}$, Marco Barozzi ${ }^{4}$, Marcello Bisulli ${ }^{3}$, Emanuele Russo ${ }^{1}$, Vittorio Albarello ${ }^{1}$ and Vanni Agnoletti ${ }^{1}$

${ }^{1}$ Anesthesia and Intensive Care Unit, Emergency Department, Maurizio Bufalini Hospital, Viale Ghirotti 286, 47521, Cesena, Italy

${ }^{2}$ General Surgery Unit, Emergency Department, Maurizio Bufalini Hospital, Viale Ghirotti 286, 47521, Cesena, Italy

${ }^{3}$ Radiology Unit, Emergency Department, Maurizio Bufalini Hospital, Viale Ghirotti 286, 47521, Cesena, Italy

${ }^{4}$ Emergency Medicine Unit, Emergency Department, Maurizio Bufalini Hospital, Viale Ghirotti 286, 47521, Cesena, Italy

"Corresponding author: Emiliano Gamberini, Anesthesia and Intensive Care Unit, Emergency Department, Maurizio Bufalini Hospital, Viale Ghirotti 286, 47521, Cesena, Italy, Tel: +390547352111; E-mail: emiliano.gamberini@ausIromagna.it

Rec date: June 19, 2017; Acc date: July 17, 2017; Pub date: July 19, 2017

Copyright: (c) 2017 Gamberini E. This is an open-access article distributed under the terms of the creative commons attribution license, which permits unrestricted use, distribution, and reproduction in any medium, provided the original author and source are credited.

\begin{abstract}
Introduction: Resuscitative endovascular balloon occlusion of the aorta has been used in various clinical settings to elevate blood pressure in the setting of shock, even if the evidence base is weak with no clear indications.

Case presentation: We report a case of traumatic hemorrhagic shock in which this technique was used in an unusual manner, treating obvious arterial abdominal bleeding associated with suspected pelvic arterial bleeding, in a Trauma Center where hybrid angiographic-surgical suite is not available. A 35-year-old man was involved in a traffic accident within 2 trucks. He was transported to the Major Trauma Center of an Integrated Trauma System where emergent laparotomy confirmed massive hepatic rupture and a bleeding control was obtained by large abdominal packing. Trauma team decided to considerate Resuscitative Endovascular Balloon Occlusion of the Aorta, positioning a deflated balloon in zone III to eventually manage a pelvic arterial hemorrhage, while performing Bogota Bag. Suddenly a new abdominal arterial bleeding was noted through Bogota Bag. Because Pringle maneuver was considered too difficult in this case because of liver hilum injury, the balloon was moved cranially with the aim to reach zone I. Introducer sheath displacement occurred at this time, and the balloon was then only partially inflated in zone II, usually considered too dangerous, and immediately the target systolic blood pressure of $90 \mathrm{mmHg}$ was obtained. Transfer the patient into interventional radiology suite was then feasible and embolization of active bleeding by right hepatic artery and superior mesenteric artery branch, missed during first laparotomy, were performed. Balloon was definitely deflated after 50 minutes. The patient was discharged by the hospital 113 days later, fully recovered with long lasting motor rehabilitation program.
\end{abstract}

Discussion: Partial zone II Resuscitative Endovascular Balloon Occlusion of the Aorta in this particular case allowed overcoming procedural mistakes without major complications and with good clinical outcome.

Conclusion: Judicious manage of REBOA inflation time and amount, together with multidisciplinary contemporary damage control strategy with clear and effective team leading, is the key to effectively resuscitate multiple trauma shocked patients.

Keywords: REBOA; Hemorrhagic shock; Zone II; Liver injury; Pelvic injury; Multiple trauma; Trauma leader; Trauma system; Trauma center; Trauma team

\section{Introduction}

Hemorrhagic shock is a major cause of death in the acute care setting $[1,2]$. Although the main aim of resuscitation is to stop the hemorrhage and restore circulating blood volume, persistent hemorrhage can be rapidly fatal. In major trauma, uncontrolled bleeding is the first cause of potentially preventable death [3-5]. Resuscitative endovascular balloon occlusion of the aorta (REBOA) has been used in a variety of clinical settings (postpartum hemorrhage, upper gastrointestinal hemorrhage, pelvic hemorrhage during pelvic/ sacral tumor surgery, traumatic abdominopelvic hemorrhage, ruptured aneurysm abdominal aorta [6-9] to successfully elevate central blood pressure in the setting of shock, even if the evidence base is weak with no clear indications. The effectiveness in this clinical target seems to be confirmed by recent pooled analysis [10], that demonstrated an increase in mean systolic pressure by following REBOA use, but benefits in terms of overall reduction of mortality in trauma patients is controversial [11,12] (Table 1).

Prospective data collection is underway in the form of American Association for the Surgery of Trauma sponsored observation studies [13] and a European Registry [14] which should permit the consistent recording of REBOA-specific data such as indications and outcome. The conventional aim of REBOA is to maintain cerebral and coronary 
Citation: Gamberini E, Fabbri N, Taioli A, Martino C, Barozzi M, et al. (2017) Partial Zone II Resuscitative Endovascular Balloon Occlusion of the Aorta in Management of Multiple Trauma with Combined Abdominal and Pelvic Injury. J Trauma Treat 6: 382. doi: $10.4172 / 2167-1222.1000382$

Page 2 of 5

circulation to temporarily control arterial hemorrhage from the injured organ via occlusion using balloon inflation of the aortic lumen, keeping the patients alive until you can get them into the operating theatre or interventional radiology suite for the definitive control of their hemorrhage [5].

\begin{tabular}{|c|c|c|c|c|c|c|}
\hline References & Year & Study Type & $\mathbf{n}$ & Zone & Shock & Mortality \\
\hline [24] & 1954 & Case series & 2 & 1 & Y & $2 / 2(100 \%)$ \\
\hline [25] & 1986 & Case series & 15 & I & Y & $\begin{array}{l}13 / 15 \\
(86.7 \%)\end{array}$ \\
\hline [26] & 1986 & Case report & 1 & III & $\mathrm{Y}$ & Nil \\
\hline [27] & 1989 & Case series & 21 & 1 & $\mathrm{Y}$ & $\begin{array}{l}14 / 21 \\
(66.7 \%)\end{array}$ \\
\hline [28] & 2001 & Case report & 1 & 1 & $\mathrm{Y}$ & Nil \\
\hline [29] & 2010 & Case series & 13 & III & Y & $7 / 13$ (53.8\%) \\
\hline [30] & 2013 & Case series & 6 & $\begin{array}{l}|\times 4 ;| I \mid \\
\times 2\end{array}$ & Y & $2 / 6(33.3 \%)$ \\
\hline [31] & 2013 & Case series & 5 & III & $\mathrm{Y}$ & Unknown \\
\hline [32] & 2014 & Case report & 1 & III & Y & Nil \\
\hline [33] & 2014 & Case report & 1 & III & $\mathrm{N}$ & Nil \\
\hline [34] & 2015 & Case series & 7 & 1 & Y & $1 / 7(14.3 \%)$ \\
\hline [35] & 2015 & Case series & 14 & 1 & $\mathrm{Y}$ & $9 / 14$ (64.3\%) \\
\hline [11] & 2015 & Cohort study & 452 & 3 & $\mathrm{Y}$ & $\begin{array}{l}343 / 352 \\
(75.9 \%)\end{array}$ \\
\hline [36] & 2015 & Case series & 24 & 1 & $\mathrm{Y}$ & $\begin{array}{l}10 / 24 \\
(41.7 \%)\end{array}$ \\
\hline [12] & 2015 & Cohort study & 24 & $\begin{array}{l}1 \times 19 ; \\
3 \times 5\end{array}$ & Y & $\begin{array}{l}15 / 24 \\
(62.5 \%)\end{array}$ \\
\hline [37] & 2015 & Cohort study & 397 & - & Y & $\begin{array}{l}\text { Not } \\
\text { applicable }\end{array}$ \\
\hline [38] & 2015 & Cohort study & 24 & - & $\mathrm{Y}$ & $\begin{array}{l}\text { Not } \\
\text { applicable }\end{array}$ \\
\hline [39] & 2015 & - & - & - & - & $\begin{array}{l}\text { Not } \\
\text { applicable }\end{array}$ \\
\hline [40] & 2016 & Cohort study & 625 & - & Y & $\begin{array}{l}386 / 625 \\
(61.8 \%)\end{array}$ \\
\hline [41] & 2016 & Cohort study & 46 & $\begin{array}{l}|\times 33 ;||| \\
\times 1,|I| \times \\
8\end{array}$ & Y & $\begin{array}{l}33 / 46 \\
(71.7 \%)\end{array}$ \\
\hline [42] & 2016 & Case report & 1 & 1 & Y & Nil \\
\hline
\end{tabular}

Table 1: Summary of the reports relating to balloon occlusion in traumatic patients.

Endovascular balloon placement is performed by fluoroscopic guidance or post-placement $\mathrm{x}$-ray confirmation after blind insertion [15]. Recently it has been proposed an ultrasound guided wire advancement [16]. This is an important finding because the need for fluoroscopy is a major limitation to the use of REBOA in settings with limited medical infrastructure. Aortic level of balloon inflation usually is classically reported by a 3 zone classification: zone I thoracic aorta from left subclavian and celiac artery, zone II between celiac and renal artery, zone III infrarenal placement $[17,18]$.

For bleeding in abdominal cavity the REBOA balloon is placed in zone I. For pelvic bleeding, generally from branches of iliac arteries, the balloon is placed in the distal aorta (zone III). Zone II is not used currently. It is also described the prophylactic balloon placement in hemodynamically stable patients at risk of significant hemorrhage [10]. Positioning could lead to device-related morbidity (3.7\%) and mortality $(0.8 \%)$ by arterial injury, insertion site complications and balloon-related thromboembolic events [10]. We present a case in which balloon was positioned and inflated in zone II for technical problem during the procedure, Partial inflation to get controlled hypotensive target, together with hemocoagulative resuscitation and direct bleeding control, allowed good outcome without major side effects.

\section{Case Presentation}

A healthy Italian 35-year-old truck driver man was involved in a traffic accident with another truck. Helicopter Medical Emergency System (HEMS) was activated and after the primary survey the patient showed a Glasgow Coma Scale of 14 (E4, V4, M6), respiratory rate $>30 / \mathrm{min}$, heart rate (HR) 120beat/min and Blood Pressure (BP) of $100 / 80 \mathrm{mmHg}$. Extrication lasted about 60 minutes because of the massive disruption of the truck cabin. Rapid Sequence Intubation for severe respiratory failure was performed. A crystalloids solution infusion started and a pelvic binder was applied to prevent potential further injury. The patient was transported to the Emergency Department (ED) of Bufalini Hospital in Cesena, Italy while activating Trauma Team (TT) and Early Coagulation Support Protocol [19].

In ED TT confirmed HEMS doctor primary survey despite $2000 \mathrm{ml}$ of crystalloids solution already infused. Chest X-ray, Pelvic X-ray and Focus Assessed Sonography in Trauma was performed, showing left hypertensive pneumothorax, multiple pelvic fracture closed with pelvic binder, massive liver disruption and hemoperitoneum. Left side decompressive simple thoracostomy was then immediately performed with slight respiratory and hemodynamic improvement and the patient was moved to the Operating Room (OR) for emergency laparotomy while infusing type 0 Rh-negative Packed Red Blood Cells (PRBC), Fibrinogen Concentrate (FC) and Tranexamic Acid (TA) with high flow warming infusion system. The laparotomy showed massive hepatic rupture and bleeding control was obtained by 33 gauzes packing. Radial arterial catheter was positioned to measure invasive BP and fluid infusion was stopped to evaluate the hemodynamic state.

Peripheral Oxygen Saturation $\left(\mathrm{SpO}_{2}\right)$ was than measurable $98 \%$ for the first time, with inspired Oxygen inspired Fraction $\left(\mathrm{FiO}_{2}\right)$ of 1 . Hemogasanalysis at that time revealed relative hypoxia $120 \mathrm{PaO}_{2} / \mathrm{FiO}_{2}$ ratio, hypercarbia $67 \mathrm{mmHg}$ partial pressure arterial $\mathrm{CO}_{2}$, severe mixed acidosis pH 7.009, Base Excess $-14 \mathrm{mmol} / \mathrm{L}$ and Lactate 8.63 $\mathrm{mmol} / \mathrm{L}$. TT was evaluating clinical conditions to understand if patient was stable enough to be moved to Computed Tomography (CT) room outside the OR in order to get total body CT scan. No information about the presence of arterial pelvis hemorrhage was available at that moment. Surgeons and team leader decided to insert a deflated REBOA in zone III to eventually manage a pelvic arterial hemorrhage. Surgeons performed a Bogota Bag [20] to manage the patient with open abdomen assessing a secondary survey, while BP increased to $110 / 70 \mathrm{mmHg}$ and $\mathrm{HR}$ was $80 / \mathrm{min}$. Bilateral thoracostomy tubes were positioned for the definitive treatment of the left and suspected right 
Citation: Gamberini E, Fabbri N, Taioli A, Martino C, Barozzi M, et al. (2017) Partial Zone II Resuscitative Endovascular Balloon Occlusion of the Aorta in Management of Multiple Trauma with Combined Abdominal and Pelvic Injury. J Trauma Treat 6: 382. doi: $10.4172 / 2167-1222.1000382$

Page 3 of 5

pneumothorax. Suddenly arterial bleeding was noted through the Bogota Bag and BP dropped to $75 / 45 \mathrm{mmHg}$. Surgeons evaluated that Pringle maneuver was too difficult and dangerous in this particular case for the huge retroperitoneal supramesocolic hematoma and hepatic hilum injury. Already placed deflated REBOA was then moved up with the aim to inflate it in zone 1 , but unfortunately introducer sheath displacement occurred at this time. Balloon was then partially inflated in upper Zone II (Figure 1) to obtain a Systolic BP of 90-100 mmHg.
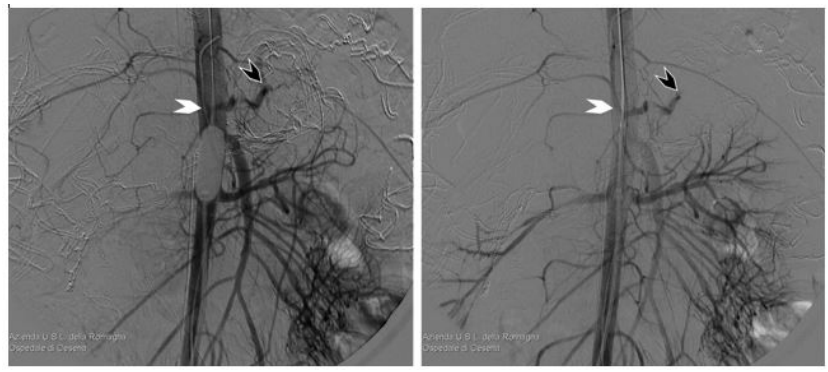

Figure 1: Aortography showing vasospasm of celiac tripod ostium (white arrow) and splenic artery (black arrow) with inflated balloon (left figure) and deflated balloon (right figure).

Patient was then transferred into interventional radiology suite, where interventional radiologist detected active bleeding from right hepatic artery and from a superior mesenteric artery branch. This last mesenteric arterial bleeding was missed during laparotomy for large mesocolon hematoma. Celiac Tripod vasospasm probably induced by balloon inflation in zone II made the procedure more difficult than usual. Bleeding lesions were treated by embolization and REBOA was definitely deflated after 50 minutes, while arterial pelvic hemorrhage was excluded by complete angiographic exam. A total of $3900 \mathrm{ml}$ PRBC, $5400 \mathrm{ml}$ Fresh Frozen Plasma, $600 \mathrm{ml}$ Platelets Concentrate, 4 gr FC and 2gr TA was infused.

Hemo-coagulative resuscitation was guided by point of care thromboelastometry. Systolic BP remained constantly above 100 $\mathrm{mmHg}$ and $\mathrm{HR}$ about $90 / \mathrm{min}$ with maintenance fluid infusion. CT scan was performed before transferring the patient into the Intensive Care Unit (Figure 2). The exam revealed also sternum fracture, spleen contusion without bleeding and previously missed left posterior diaphragmatic herniation of stomach fundus, multiple pelvic unstable injury (bilateral acetabular fracture, bilateral superior pubic and ischiopubic rami, right vertical sacral ala fracture). TT decided to delay surgical diaphragmatic hernia repair because of severe traumatic coagulopathy and improved gas exchange with $280 \mathrm{PaO}_{2} / \mathrm{FiO}_{2}$ ratios at Positive End Expiratory Pressure of $5 \mathrm{~cm} \mathrm{H}_{2} \mathrm{O}$. Pelvic fractures eternal fixation was performed bedside during Intensive Care Unit resuscitation, allowing pelvic binder removal. Injury Severity Score [21,22] was 66 and Abbreviated Injury Scale was 5 abdominal, 5 thoracic and 4 bone.

In day 2 Mean Arterial Pressure was $60 \mathrm{mmHg}$ without vasopressors infusion, Cardiac Index was $2.9 \mathrm{~L} / \mathrm{min}$, mixed venous oxygen saturation was $70 \%, \mathrm{BE}$ was $-0.5 \mathrm{mmol} / \mathrm{L}$. The patient was anuric with hysovolemic continuous renal replacement therapy. Lactate levels were continuously high for hepatic failure. Surgical second look was performed 42 hours later.
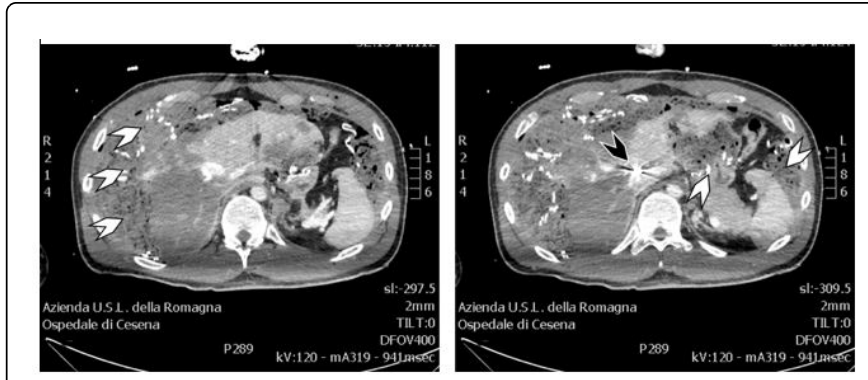

Figure 2: Abdomen CT scan showing massive hepatic injury without active bleeding. Black arrow: embolization coil in right hepatic artery. White arrows: packing gauzes around liver and spleen.

The abdomen was de-packed with no re-bleeding, the diaphragmatic hernia was reduced and primary synthesis of abdomen wall was uneventfully obtained. Serum Creatinine levels reached 6.63 $\mathrm{mg} / \mathrm{dL}$ with the need of renal replacement therapy for 78 days, mainly performed by continuous veno-venous hemofiltration. Pelvic external fixation was removed at day 40 . The patient was discharged by the hospital 113 days later almost fully recovered, with long lasting motor rehabilitation program.

\section{Discussion}

The trauma patient described above presented hemorrhagic liver injury and suspected hemorrhagic pelvic arterial injury. In order to evaluate, identify and treat the leading cause of shock, REBOA was first positioned deflated in zone III while performing simultaneously Damage Control laparotomy for hepatic packing, to treat potential coexisting pelvic arterial bleeding. After performing abdominal closure using Bogota bag, patient was again hemodynamically unstable and REBOA was moved to upper Zone II instead of Zone I for introducer sheath displacement during the procedure. Partial inflation in this position caused a transient occlusion of celiac tripod with a secondary vasospasm in the territory of hepatic artery and a contemporary improvement of invasive BP. The interventional radiologist was able to visualize the celiac tripod and to perform embolization of right hepatic artery and superior mesenteric artery branch, where a previously missed bleeding was detected.

The procedure was effective in controlling the bleeding and hemorrhage control was achieved. Partial inflation with controlled hypotensive target allowed benefits overcome risks of a defective procedure. REBOA adoption, even in a potentially dangerous position, gave authors time to move patient from OR to angiographic room (not available at the moment in our hospital a hybrid surgical angiographic suite) [23-41] and time to find the primary source in a severe and multiple hemorrhagic trauma, with good clinical outcome.

\section{Conclusion}

Authors think that REBOA partial inflation with controlled hypotensive target pressure, together with best standard care of trauma patients, could decrease REBOA-related morbidity and increase its efficacy in treating abdominopelvic traumatic hemorrhagic shock. Judicious manage of REBOA inflation time and amount, together with multidisciplinary contemporary damage control strategy with clear 
Citation: Gamberini E, Fabbri N, Taioli A, Martino C, Barozzi M, et al. (2017) Partial Zone II Resuscitative Endovascular Balloon Occlusion of the Aorta in Management of Multiple Trauma with Combined Abdominal and Pelvic Injury. J Trauma Treat 6: 382. doi: $10.4172 / 2167-1222.1000382$

Page 4 of 5

and effective team leading, is the key to effectively resuscitate multiple trauma shocked patients.

\section{References}

1. Davis JS, Satahoo SS, Butler FK, Dermer H, Naranjo D, et al. (2014) An analysis of prehospital deaths: Who can we save? J Trauma Acute Care Surg 77: 213-218.

2. Morrison JJ, Ross JD, Houston R, Watson JD, Sokol KK, et al. (2014) Use of resuscitative endovascular balloon occlusion of the aorta in a highly lethal model of noncompressible torso hemorrhage. Shock 41: 130-137.

3. Bansal V, Fortlage D, Lee J, Costantini T, Potenza B, et al. (2009) Hemorrhage is more prevalent than brain injury in early trauma deaths: the golden six hours. Eur J Trauma Emerg Surg 35: 26-30.

4. Tien HC, Spencer F, Tremblay LN, Rizoli SB, Brenneman FD (2007) Preventable deaths from hemorrhage at a level I Canadian trauma center. J Trauma 62: 142-146.

5. Tsurukiri J, Akamine I, Sato T, Sakurai M, Okumura E, et al. (2016) Resuscitative endovascular balloon occlusion of the aorta for uncontrolled haemorrahgic shock as an adjunct to haemostatic procedures in the acute care setting. Scand J Trauma Resusc Emerg Med 24: 13.

6. Morrison JJ, RasmussenTE (2012) Non compressible torso haemorrhage: are view with contemporary definitions and management strategies. Surg Clin North Am 92: 843-885.

7. Laine L (2012) Upper gastrointestinal bleeding. Clin Updat 14: 1-4.

8. Carroli G, Cuesta C, Abalos E, Gulmezoglu AM (2008) Epidemiology of post-partum haemorrhage: A systematic review. Best Pract Res Clin Obstet Gynaecol 22: 999-1012.

9. Nordon IM, Hinchliffe RJ, Loftus IM, Thompson MM (2011) Pathophysiology and epidemiology of abdominal aortic aneurysms. Nat Rev Cardiol 8: 92-102.

10. Morrison JJ, Galgon RE, Jansen JO, Cannon JW, Rasmussen TE, et al. (2016) A systematic review of the use of resuscitative endovascular balloon occlusion of the aorta in the management of hemorrhagic shock. J Trauma Acute Care Surg 80: 324-334.

11. Norii T, Crandall C, Terasaka Y (2015) Survival of severe blunt trauma patients treated with resuscitative endovascular balloon occlusion of the aorta compared with propensity score-adjusted untreated patients. J Trauma Acute Care Surg 78: 721-728.

12. Moore LJ, Brenner M, Kozar RA, Pasley J, Wade CE, et al. (2015) Implementation of resuscitative endovascular balloon occlusion of the aorta as an alternative to resuscitative thoracotomy for non-compressible truncal hemorrhage. J Trauma Acute Care Surg 79: 523-532.

13. http://www.aast.org/Default.aspx.

14. https://www.abotraumaregistry.com/

15. Morrison JJ, Rasmussen TE (2012) Non-compressible torso hemorrhage: A review with contemporary definitions and management strategies. Surg Clin North Am 92: 843-858.

16. Linnebur M, Inaba K, Haltmeier T, Rasmussen TE, Smith J, et al. (2016) Emergent non-image guided REBOA catheter placement: A cadaverbased study. J Trauma Acute Care Surg 81: 453-457.

17. Guliani S, Amendola M, Strife B, Morano G, Elbich J, et al. (2015) Central aortic wire confirmation for emergent endovascularprocedures: As fast as surgeon-performed ultrasound. J Trauma Acute Care Surg 79: 549-554.

18. Stannard A, Eliason JL, Rasmussen TE (2011) Resuscitative endovascular balloon occlusion of the aorta (REBOA) as an adjunct for hemorrhagic shock. J Trauma 71: 1869-1872.

19. Nardi G, Agostini V, Rondinelli B, Russo E, Bastianini B, et al. (2015) Trauma-induced coagulopathy: impact of the early coagulation support protocol on blood product consumption, mortality and costs. Crit Care Med 19: 83

20. Kreiz BE, De Mol Van Otterloo AJ, Kreis RW (2013) Open abdomen management: A review of its history and a proposed management algorithm. Med Sci Monit 19: 524-533.
21. Baker SP, O'Neill B, Haddon W, Long WB (1974) The injury severity score: A method for describing patients with multiple injuries and evaluating emergency care. J Trauma 14: 187-196.

22. Copes WS, Champion HR, Sacco WJ, Lawnick MM, Keast SL, et al. (2010) The injury severity score revisited. J Trauma 28: 69-77.

23. Fehr A, Beveridge J, D’Amours SD, Kirkpatrick AW, Ball CG (2016) The potential benefit of a hybrid operating environment among severely injured patients with persistent hemorrhage: How often could we get it right? J Trauma Acute Care Surg 80: 457-460.

24. Hughes CW (1954) Use of an intra-aortic balloon catheter tamponade for controlling intra-abdominal hemorrhage in man. Surgery 36: 65-68.

25. Low RB, Longmore W, Rubinstein R, Flores L, Wolvek S (1986) Preliminary report on the use of the percluder occluding aortic balloon in human beings. Ann Emerg Med 15: 1466-1469.

26. Wolf RK, Berry RE (1986) Transaxillary intra-aortic balloon tamponade in trauma. J Vasc Surg 4: 95-97.

27. Gupta BK, Khaneja SC, Flores L, Eastlick L, Longmore W, et al. (1989) The role of intra-aortic balloon occlusion in penetrating abdominal trauma. J Trauma 29: 861-865.

28. Matsuoka S, Uchiyama K, Shima H, Ohishi S, Nojiri Y, et al. (2001) Temporary percutaneous aortic balloon occlusion to enhance fluid resuscitation prior to definitive embolization of post-traumatic liver hemorrhage. Cardiovasc Intervent Radiol 24: 274-276.

29. Martinelli T, Thony F, Decléty P, Sengel C, Broux C, et al. (2010) Intraaortic balloon occlusion to salvage patients with life- threatening hemorrhagic shocks from pelvic fractures. J Trauma 68: 942-948.

30. Brenner ML, Moore LJ, Dubose JJ, Tyson GH, McNutt MK, et al. (2013) A clinical series of resuscitative endovascular balloon occlusion of the aorta for hemorrhage control and resuscitation. J Trauma Acute Care Surg 75: 506-511.

31. Wang G, Zhou D, Shen WJ, Xin M, He J, et al. (2013) Management of partial traumatic hemipelvectomy. Orthopedics 36: e1340-1345.

32. Uchida K, Homma H, Oda J, Yukioka T, Nagai N, et al. (2015) Hemostasis with emergently modified application of intra-aortic balloon occlusion in a patient with impending cardiac arrest following blunt proximal thigh amputation. Acute Med Surg 2: 69-71.

33. Green KD, Waked A, Majeed U, Fudim M, Robbins MA, et al. (2014) Percutaneous management of RetroFlex 3 balloon rupture and separation of the Edwards Sapien delivery system. Tex Heart Inst J 41: 641-644.

34. Ogura T, Lefor AT, Nakano M, Izawa Y, Morita H (2015) Nonoperative management of hemodynamically unstable abdominal trauma patients with angioembolization and resuscitative endovascular balloon occlusion of the aorta. J Trauma Acute Care Surg 78: 132-135.

35. Irahara T, Sato N, Moroe Y, Fukuda R, Iwai Y, et al. (2015) Retrospective study of the effectiveness of Intra-Aortic Balloon Occlusion (IABO) for traumatic haemorrhagic shock. World J Emerg Surg 10: 1.

36. Saito N, Matsumoto H, Yagi T, Hara Y, Hayashida K, et al. (2015) Evaluation of the safety and feasibility of resuscitative endovascular balloon occlusion of the aorta. J Trauma Acute Care Surg 78: 897-903.

37. Barnard EB, Morrison JJ, Madureira RM, Lendrum R, Fragoso-Iñiguez $\mathrm{M}$, et al. (2015) Resuscitative endovascular balloon occlusion of the aorta (REBOA): a population based gap analysis of trauma patients in England and Wales. Emerg Med J 32: 926-932.

38. Belenkiy SM, Batchinsky AI, Rasmussen TE, Cancio LC (2015) Resuscitative endovascular balloon occlusion of the aorta for hemorrhage control: Past, present, and future. J Trauma Acute Care Surg 79: S236-242.

39. Inoue J, Shiraishi A, Yoshiyuki A, Haruta K, Matsui H, et al. (2016) Resuscitative endovascular balloon occlusion of the aorta might be dangerous in patients with severe torso trauma:

40. DuBose JJ, Scalea TM, Brenner M, Skiada D, Inaba K, et al. (2016) The AAST prospective aortic occlusion for resuscitation in trauma and acute care surgery (AORTA) registry: Data on contemporary utilization and outcomes of aortic occlusion and resuscitative balloon occlusion of the aorta (REBOA). J Trauma Acute Care Surg 81: 409-419. 
Citation: Gamberini E, Fabbri N, Taioli A, Martino C, Barozzi M, et al. (2017) Partial Zone II Resuscitative Endovascular Balloon Occlusion of the Aorta in Management of Multiple Trauma with Combined Abdominal and Pelvic Injury. J Trauma Treat 6: 382. doi: $10.4172 / 2167-1222.1000382$

Page 5 of 5

41. Matsumoto N, Sogabe O, Yoshida O, Endo I, Yamamoto S, et al. (2016) The usefulness of resuscitative endovascular balloon occlusion of the aorta in detecting the source of a hemorrhage due to abdominal blunt trauma. Am J Emerg Med 34: e1-2057. 